\title{
Organizational determinants in the procurement and transplantation pathway: a review
}

\author{
This article was published in the following Dove Press journal: \\ Transplant Research and Risk Management \\ 17 December 2014 \\ Number of times this article has been viewed
}

\section{Maria Triassi' \\ Elena Giancotti ${ }^{2}$ \\ Antonio Nardone' \\ Giulia Mancini ${ }^{3}$ \\ Fabiana Rubba'}

'Public, Preventive and Social

Medicine School, University

Federico II of Naples, Naples, Italy;

2Procurement and Transplantation Coordination, Naples, Italy; ${ }^{3}$ Sociology

Unit, G D'annunzio University, Chieti-

Pescara, Italy
Correspondence: Fabiana Rubba

Public Health department, University Federico II of Naples, Hospital Direction, Via Pansini 5, 80I3I Naples, Italy Email fabiana.rubba@unina.it
Introduction: The growing disparity between organ availability for transplantation and the number of patients in need has challenged the donation and transplantation community to develop innovative processes, ideas, and techniques to bridge this gap. Advances in the sharing of best practices in the donation community have contributed greatly to this aim over the past 5 years. Studies published during the past five years (2010-2014) were analyzed to gain insight on the evolving organizational areas and tools that the procurement and transplantation pathways have been focused on. The hypothesis assessed is that networking and efficacious handling of this complex path may be ameliorated by an adaptive organizational toolbox.

Methods: A thorough search has been conducted using various databases, ie, Cochrane library, PubMed, EMBASE, Federico II University Open Archive. The evidence was considered following the Effective Practice and Organization of Care Group checklist. Prevalent organizational attitudes and areas were assessed, and various scenarios were analyzed. Initially, all titles and abstracts were screened. In the next phase, the full text of all abstracts considered potentially relevant by at least one of the reviewers was evaluated. Inconsistencies in decision-making within this second phase were solved based on consensus between both reviewers. In this phase, for every study we defined whether the organization was considered relevant and what the scenario was. The information was extracted from each study based on bibliographic details (author, journal, year of publication, and language). As many as 1,071 studies were analyzed, and 81 were selected as potentially relevant.

Results: We found three prevalent areas of interest focused on organizational elements: global organizational strategies scenario, clinical hospital organization, and citizenship and social scenario.

Conclusion: We reached the conclusion that organization has a central role in different scenarios of procurement and transplantation in a continuum from government to hospital (the core of the system) and finally among citizens. A standardized hospital pathway definitely remains the essential step in order to ameliorate either procurement or transplantation.

Keywords: transplant procurement, management, organizational tool, network

\section{Introduction}

A crucial problem of contemporary medicine is the growing disparity between organ availability for transplantation and the number of patients in need of donation, which has involved and inspired the transplantation community to develop innovative processes, ideas, and techniques to bridge this gap. A large contribution has come from advances in the sharing of best practices in the donation community over the past 5 years. Data were similar from country to country (the largest number of transplants were performed in the USA, People's Republic of China, Brazil, and India, while the 
greatest population access to transplantation was in Austria, USA, Croatia, Norway, Portugal, and Spain).

There are still many limitations in access to transplantation across the globe. Techniques for organ preservation and organ resuscitation have allowed the number of transplanted organs to increase. Transplant surgery is a landmark in medicine, and both living donations and deceased donor donations are now recognized.

However, no country in the world generates sufficient organs from these sources to meet the needs of their citizens. Austria, USA, Croatia, Norway, Portugal, and Spain stand out as countries with high rates of deceased organ donors, and most developed countries are trying to emulate their success. Worldwide currently there is a need for 1 million transplants, with almost 10,000 of these in Italy alone. This review tries to highlight processes, ideas, and techniques in organ donation concerning the necessary managerial and organizational tools.

In particular, studies published in the past 5 years (2010-2014) were analyzed to gain insight in the evolving scenario of organizational areas and tools. We restricted the analysis to solid organ procurement and transplantation, as tissue and cellular milieu have different needs. The organizational hypothesis assessed is whether management and organizational determinants could impact networking and efficacious participative handling of this complex path and where organizational tools can be applied.

\section{Search methods}

A thorough search has been conducted using various databases: Cochrane library, PubMed, EMBASE, and Federico II University Open Archive. Mesh terms were "transplantation", "procurement", and "organization", and time frame was limited to studies published from 2010-2014. Evidence was assessed according to almost all points of the Checklist for Refereeing Protocols for Systematic Reviews issued by the Effective Practice and Organization of Care Group, Cochrane Collaboration. ${ }^{1}$ Prevalent organizational attitudes and areas were assessed, and various scenarios were analyzed. In the initial first phase, all titles and abstracts were screened. In the next phase, the full text of all abstracts considered potentially relevant by at least one of the abstract reviewers were assessed and evaluated. Inconsistencies in decision making within this second phase were solved based on consensus between both reviewers. In this phase, for every study we defined their relevance and what the scenario was. Information was extracted from each study using bibliographic details (author, journal, year of publication, and language).

\section{Results}

As many as 1,071 studies were analyzed, and 81 were selected as potentially relevant.

We found three prevalent areas of interest focused on organizational elements (Figure 1):

- global organizational strategies scenario;

- clinical hospital organization; and

- citizenship, social scenario.

Among these areas, detailed themes were restructured focusing on studies where prevalent organizational intervention could be planned in order to generate an adaptive toolbox particular to every context. Table 1 shows the organizational tools sorted by scenarios.

In general, the author's effort started with the belief that there is need to have a point of view on how a decision can be made. This was the goal of our search. From an organizational standpoint, the first task is to define a point of view on future actions, or what we call "forecast, handling different options in order to generate a value". Finally, a value can be created in the practice pathways of care and choosing a strategy, and often a real choice requires having more alternatives. ${ }^{2}$

A strategy is incomplete until it is possible to roll back the future into tangible, proximate goals, until it is possible to communicate very clearly and convey what has to change for people, and until resources have been shifted. We believe this type of action can lead to a change in people's attitudes.

As to procurement and transplantation options, the challenge is to design a social process so that people can fully share the importance of these problems and therefore accept this option.

\section{Discussion}

\section{Studies allocated to global organizational strategies and toolbox scenario}

The deceased donor organ donation process can be viewed as a continuum from the initial donor assessment all the way through to organ transplantation. Organization may support the linking procurement and transplantation phase either in hospital practice or in the social environment.

As a matter of fact, to maximize the supply and quality of the deceased donor organ pool, every step has to be analyzed and handled, identifying the contextual organizational toolbox. ${ }^{3,4}$ There are international and national task forces and strategies to implement transplantation and procurement management that involve scientific societies (The Transplantation Society has established the Global 


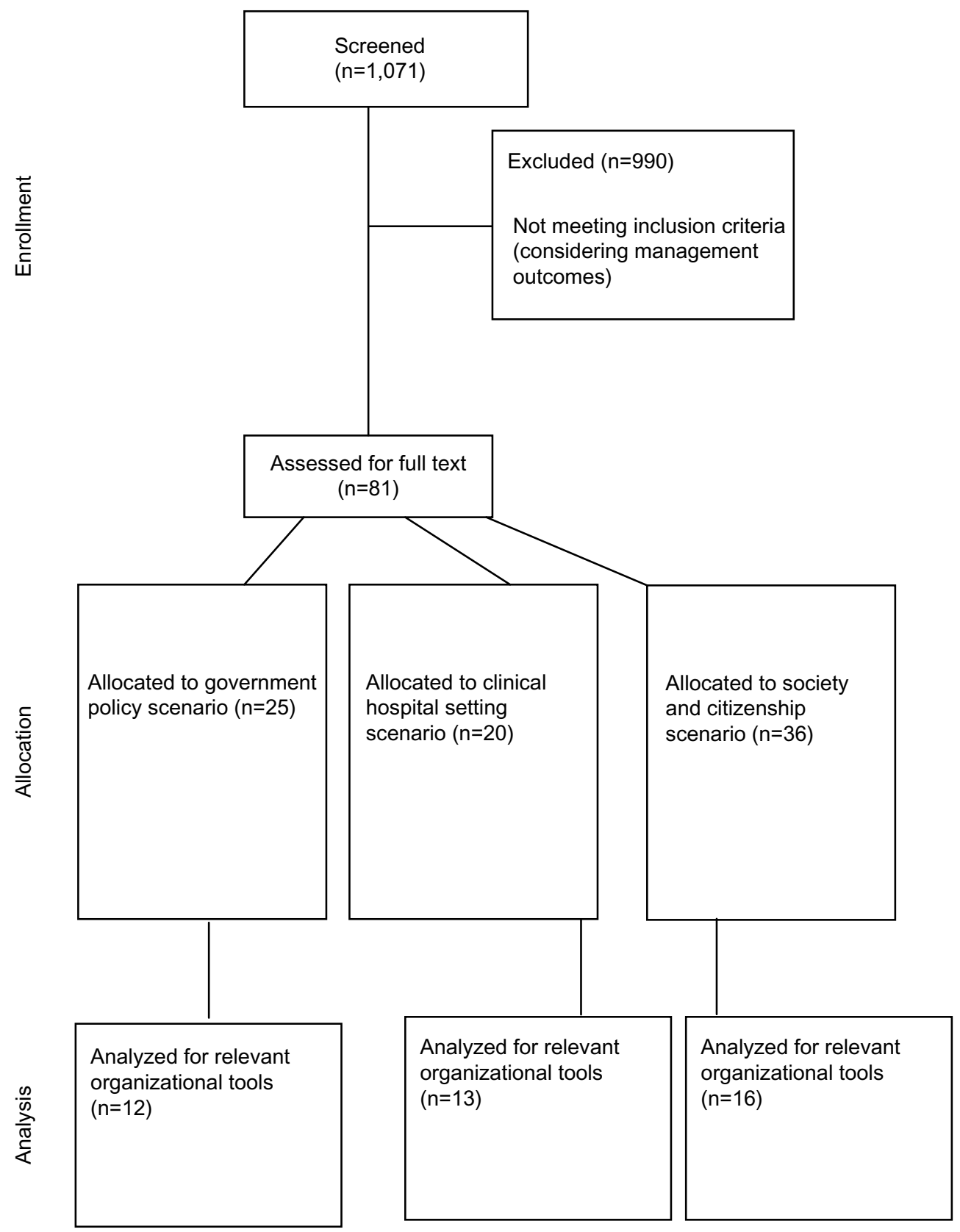

Figure I CONSORT diagram showing the analysis of studies through each stage. Abbreviation: CONSORT, Consolidated Standards of Reporting Trials.

Table I Organizational toolboxes sorted by scenarios

\begin{tabular}{|c|c|c|}
\hline Scenario & $\begin{array}{l}\text { Organizational } \\
\text { toolbox }\end{array}$ & $\begin{array}{l}\text { Where the toolbox } \\
\text { can be applied }\end{array}$ \\
\hline $\begin{array}{l}\text { Global } \\
\text { organizational } \\
\text { strategies }\end{array}$ & $\begin{array}{l}\text { Networking, sharing } \\
\text { information }\end{array}$ & $\begin{array}{l}\text { Scientific societies } \\
\text { Governments' policies }\end{array}$ \\
\hline $\begin{array}{l}\text { Hospital clinical } \\
\text { strategies }\end{array}$ & Hospital lean pathway & $\begin{array}{l}\text { Senior management } \\
\text { level }\end{array}$ \\
\hline & Referral policy team & $\begin{array}{l}\text { Hospital team work } \\
\text { University hospitals }\end{array}$ \\
\hline $\begin{array}{l}\text { Society and } \\
\text { citizenship }\end{array}$ & $\begin{array}{l}\text { Communication Rhetoric } \\
\text { of gift implementing } \\
\text { Ethical shared debate }\end{array}$ & $\begin{array}{l}\text { Newspapers, TV/ } \\
\text { movies, social networks } \\
\text { Communities }\end{array}$ \\
\hline
\end{tabular}

Alliance for Transplantation, International Society of Nephrology Global Outreach program), or targeted fellowship training, as well as the creation of long-term institutional links between developed and developing transplant centers. ${ }^{4}$ In developing countries as well (Armenia, Ghana, and Nigeria - where none existed before, and expansion of existing programs in Belarus, Lithuania, and Tunisia), it has been possible to establish successful transplantation programs, and furthermore, assess collaboration models for dialysis and transplantation between government and the community. ${ }^{3,4}$ 
Living donation starts where deceased donor programs are well standardized and remains the mainstay of transplantation in many parts of the world, especially Asian ones. ${ }^{5}$

The developing of allocation policies is in progress. For example, the US United Network for Organ Sharing has long prided itself as being entirely egalitarian, distributing organs on a first-come, first-serve basis without regard to wealth, class, race, or other considerations. ${ }^{5,6}$ However, the United Network for Organ Sharing is now focusing on a review of policies for allocating kidneys, including the allocation of kidneys from younger donors to younger recipients. The changes also aim to result in the creation of a kidney profile index that ranks the quality of all donated kidneys. ${ }^{5-8}$

The UK-based program has been involved, first, in creating and communicating the Organ Donation Taskforce's vision for donation, and second, in introducing the structural elements in a cultural context, in clinical practice, and hospital practice; eventually, a team-structured way of working will lead to the creation of an environment in which these new elements can deliver the overall program goals. ${ }^{9}$

The Australian national approach and system is similarly structured and based on the following rules: dedicated national authority, networking of organ and tissue donation, hospital staff and systems, funding for hospitals, support for donor families, and coordinated, ongoing community and education strategy. ${ }^{9,10}$

In the European community, the Italian experience in organizing transplantation procedures may represent a relevant example of an internal development, combined with a strengthening of international networking. ${ }^{11,12}$ These results can be attributed first to the creation of an organizational network, ie, the Italian National Transplant Centre (Centro Nazionale Trapianti), and then to the establishment of a closer collaboration in the field of transplantations. Centro Nazionale Trapianti pursues two main activities: the promotion of international relationships and the participation with, or coordination of, international projects, through bilateral agreements signed between the Italian Ministry of Health and other Mediterranean countries. The gold standard has been attained in Spain, where a National Transplant Organization (ONT) was established in 1989, ${ }^{13,14}$ introducing the Transplant Donor Coordinators Spanish model - a systematic organizational model. Hospitals are reimbursed for their donation and transplantation activities, as any other medical activity performed within the public health care system. The corresponding regional health authorities assess a specific budget to cover both the human and material resources needed for the effective development of these activities within every hospital. ${ }^{13-15}$ Therefore, the organizational structure becomes crucial to obtain efficiency and clinical effectiveness along the path from donation to transplant.

The majority of Transplant Donor Coordinators are physicians or nurse coordinators. The model supposes different levels of coordination: national, regional, and hospital. ${ }^{13}$

The success of the Spanish model is frequently linked to Spain's legal framework of presumed consent. However, the success is now assessed as independent from the opting-out system for consent to donation. Furthermore, the presumed consent policy has never been strictly applied in practice; relatives posing ethical issues are always approached and always have the final say. Donation rates increase along with the growing incidence of the very well trained transplant coordinators who approach the grieving families. ${ }^{15,16}$

Networking can allow the implementation of some programs and optimization of resources. The relationship between volume and outcome is not conclusive for liver transplantation in Germany. However, data collected for a period of 3-5 years support the notion that policies influencing the regulation of the number of transplant centers should be based upon the number of effective transplants performed, weighing regional medical requirements against an optimal patient supply, meanwhile respecting a plausible risk adaption for each center. ${ }^{17}$

A different challenge is to understand the resistance to donation from a central policy perspective. The PAraDOx Study ${ }^{10}$ examines community preferences for organ donation policy in Australia. It aims to use qualitative and quantitative methods to assess community preferences for organ donation and allocation. Focus group participants from the general community, aged between 18 and 80 years, were sampled to ensure a variety of cultural backgrounds and views on organ donation.

The goal is to determine which factors influence decisions by individuals to offer their organs for donation and to determine the criteria by which, from a community-based standpoint, the community views the allocation of donor organs. Estimates of the marginal effect (importance) of each attribute on overall choice provide an estimate of the relative importance of receiving a fee and of the concern regarding the ability to influence allocation. The study overall demonstrates the effort to gain insight into a community in order to develop instruments to address the clinical tools.

Conversely, in Singapore, ${ }^{18,19}$ despite the legislation, the number of deceased organ donors that currently ranges from 7 to 9 per million population per year, remains low compared to many other developed countries. 
A paper reviewed the clinical challenges and ethical dilemmas encountered in handling this process. ${ }^{3}$ The large variance in donor actualization rates among local restructured hospitals, which ranges from $0 \%$ to $56.6 \%$ (median $8.8 \%),{ }^{19}$ suggests that the scenario may be ameliorated by a central policy. To address this hypothesis, it would be worthwhile reviewing their processes to ensure earlier identification of potential donors, avoid undue delays in diagnosing brain death, and provide optimal care of multiorgan donors. ${ }^{3,20,21}$

These findings demonstrate that society and social attitudes are crucial. Not taking society into consideration would preclude a positive attitude toward donation. Unlike other medical practices, transplantation does not only depend on technical and surgical elements but also on a strictly organizational support. ${ }^{22-24}$

Governments rely on management strategies and strategic tools. Relevant government toolboxes could include networking and sharing information. Government strategies are to be in line with a circular economy perspective. ${ }^{25}$ Within a circular economy, from the outset, the economy is designed to be regenerative. As when designing a car for remanufacture, disassembly, and de-componentization is considered, so human life can be thought as materials that currently flow off the end of the conveyer belt and go back in. De-componentization but also the overall picture in this complex milieu has to be considered.

A global strategies toolbox first can help assess a structured networking and sharing of information. Second, this can align centralization of transplantation pathways in specialized centers, centralized procurement teams, and tissue banking models. Whatever model or strategy, the crucial point is to streamline the system to maximize every effort.

\section{Procurement and transplant aligned inside hospital pathways}

In the Spanish model, a central role is attributed to hospital strategies aimed to gain donors. As a matter of fact, the detection of donors is a crucial clinical challenge that may be supported by organizational pathways and networking within the hospital.

We hypothesized that intensivist-led management of brain-dead donors would increase the number of organs recovered for transplantation. ${ }^{26-30}$ A study retrospectively analyzed this hypothesis by evaluating data from all consented adult brain-dead patients in the year before $(n=35)$ and after ( $\mathrm{n}=43$ ) implementation of an intensivist-led donor management program. ${ }^{27}$
Donor characteristics before and after implementation were similar. The results showed that, after implementation of the organ donors' support team, the overall number of organs procured for transplantation increased significantly ( 66 out of 210 potentially available organs vs 113 out of 258 potentially available organs; $P=0.008$ ). This was largely due to an increase in the number of lungs and kidneys ( 8 out of 70 potentially available lungs vs 21 out of 86 potentially available lungs; $P=0.039$ ) ( 31 out of 70 potentially available kidneys vs 52 out of 86 potentially available kidneys; $P=0.044$ ). These data verified that the institution of a donor support team may be a viable strategy to increase the number of organs available for transplantations.

Moreover, prompt recognition of all potential organ donors is critical, and this may be in the emergency department or in the intensive care unit (ICU). This hypothesis has been confirmed by the Spanish model monitoring findings and particular quality system. ${ }^{15,31}$ Hospitals are required to identify and refer all potential organ donors to the local organ procurement organization. Therefore, a hospital policy entitled Required Referral can be developed. A similar policy usually is preliminarily implemented in a large hospital trust consisting of four critical care units, ${ }^{26-31}$ as a "pilot policy" in the first instance.

By using this policy, a significant increase in potential donor referrals can be demonstrated, as well as a $200 \%$ increase in donated organs, achieved by associating organizational policies focused on ameliorating donor recognition, brain death identification, and finally, donor referral.

The standard Spanish model confers to hospital managers, particularly to clinicians - together with a supporting nurse, - the entire burden of procurement. In Spain, public hospitals are the source of most donors. The country has more ICU beds and doctors per 1,000 people compared with other nations. ${ }^{31}$ Such resources maximize the identification and maintenance of potential donors until the family is approached for donation.

The hospital-focused transplant coordinator model is one of the cornerstones of the Spanish success, and at least one team of transplant coordinators is present in every hospital authorized to procure organs and tissues with an ICU or acute beds. Transplant coordinators are responsible for identifying and evaluating donors, supporting the maintenance of potential donors in ICU, and interviewing donor families. Unlike external coordinators from organ procurement organizations in countries such as the USA or Canada, Spanish professionals are mostly ICU doctors or anesthesiologists who work part-time as in-hospital transplant coordinators. 
In other countries as well, hospital coordination is done in partnership with other professionals including public health profiles.

Spain has one of the lowest rates of family refusal of organ donation in the world. In 2009, of all interviews made, only $16.4 \%$ of families refused to donate (almost half the French rate of family refusal). This rate could be also attributable to use of very detailed protocols to identify causes of family refusals and reverse them. Similar to many countries, including France, Italy, the UK, and Canada, Spain imposes no age limit on becoming a brain-dead organ donor. Also, because the proportion of organs that cannot be transplanted increases with donor age, some organs are procured from extended-criteria donors, and to manage marginal donors we need growing expertise of professionals.

The complexity of this pathway and the need for multitask and on-demand teams composed of professionally engaged physicians and nurses skilled with older donors and recipients seem to confirm the standpoint that donor recognition has to become a knowledge management resource of the hospital CEO, which should then be applied to every hospital setting. ${ }^{35,36}$

\section{Another hospital organizational tool is waiting list handling}

While the surgical and technical problems of transplantation may have been largely resolved, and basic and translational research may address the complications in the future, the success of a worldwide shortage of organs for transplantation is focused on networking and teamwork. ${ }^{22,24}$ Waiting lists may function as a significant organizational tool by defining the candidates to transplantation and inactivity status.

For example, more than 90,000 patients in the USA await a kidney transplant, and nearly $30 \%$ of these are, at some point, classified as the temporary inactive status. ${ }^{27,28}$ This means that these patients experience an increase in waiting time but cannot be called for a transplant if an organ becomes available. There are multiple reasons for placing patients on the inactive status: hospital admission for vascular access problems, suspected lesions on preoperative screening, poor compliance with dialysis treatments, and others. Anyone of these concerns could lead to temporary inactivation until the problem is resolved. In many centers, high-risk patients are required to undergo annual re-evaluation, and failure to complete the annual testing could cause automatic inactivation until the evaluation is complete..$^{37,38}$

Placing patients on temporary inactivation creates further challenges for transplant centers, which must monitor workup results and decide whether to relist or delist a patient. There is little literature describing the characteristics and outcomes of these patients. There are questions about how the classification is used, about the main risk factors and causes for temporary inactivation, and how long it takes to reactivate these patients on the waiting list. ${ }^{37-39}$ In order to gain insight and efficacy, the deceased donor kidney transplantation program at the Federico II University Medical School in Naples experimentally has been using the Toyota model of waiting list handling. ${ }^{40}$ This approach contributes to create a digital archive of clinical data of candidates, including a computerized record. This allows fast tracking of recipients, which includes all the human leukocyte antigen (HLA) system and hyperimmunization information.

The model for end-stage liver disease (MELD) score is used to stratify candidates for liver transplantation based on objective measures of disease severity. MELD has been validated as a predictor of wait-list mortality in transplantation candidates and has been postulated as a predictor of posttransplant survival. ${ }^{41-43}$

A systematic review and critical appraisal was performed using Cochrane guidelines. There were 3,058 discrete citations identified and screened for possible inclusion. ${ }^{42}$ Any study examining the relationship between pretransplant MELD and posttransplant survival in the general transplant population was included. Thirty-seven studies met these criteria and were included in the review. There was significant clinical heterogeneity in patient populations across studies, which precluded a meta-analysis. In 15 studies, no statistically significant association between MELD and posttransplant survival was found. In the remaining 22 , some association was found. Child-Pugh (CP) scores are by far the most extensively used in both clinical practice and clinical research, and has stood the test of time for nearly 40 years. Recently, the MELD score has replaced the CP score in the USA and other countries for prioritizing liver donor allocation.

On the other hand, in some populations the non-MELD score is superior to the MELD score in accurately predicting the risk of mortality (as Iranian patients with advanced liver disease). ${ }^{43-45}$ In conclusion, the MELD score and posttransplant survival represented a low level of evidence. However, MELD remains an explicit criterion for stratifying transplant priorities, and prognostic assessment of patients with liver cirrhosis is a vital subject that often challenges the clinicians.

Social barriers to effective medical care are mandated to be routinely assessed as part of an evaluation for liver transplantation as they can create a long stay on a waiting list. ${ }^{45}$ 
A US survey study explores how frequently liver transplant programs present these barriers for patients undergoing an evaluation and whether programs with higher proportions of Medicaid patients, historically disadvantaged minority patients, and rural patients encounter social barriers more frequently. ${ }^{45}$

Results from this study demonstrated that social barriers were reported to be encountered sometimes $(10 \%-30 \%)$ or frequently $(>30 \%)$. Prevalent barriers were inadequate or unstable health insurance ( $68.9 \%$ of the programs), a chaotic social environment (63.9\%), lack of care partner (60.7\%), inability to obtain transportation (49.2\%), low educational level (36.1\%), inadequate housing (23.0\%), language barrier (19.7\%), no reliable way of contacting the patient $(16.4 \%)$, difficulty in obtaining child care (11.5\%), and food insecurity (8.2\%).

These findings suggest that inside the hospital procurement and transplant management also has a great impact.

As a matter of fact, a good coordination team can be used as a proxy of good hospital organization. This includes heterogeneous steps from mortality data extraction and epidemiological analysis to Operating Room check-out and efficacious handling of procurement and transplant arrangements.

Donor support team, however composed, and albeit adequately trained, as well as clinical expertise in waiting list handling is essential for in-house hospital strategies. Moreover, integration of healthcare and research in the procurement and transplantation pathway can help improve organization and global effectiveness. ${ }^{23,46}$

\section{Society and citizenship}

Procurement and transplantation have a crucial impact on society. Social strategies and toolboxes add the greatest value when they become central to the organization and complement (or, ideally, substitute) existing processes. ${ }^{47}$

They should not be distracting "extras" - they should be embedded in day-to-day workflow. While the true impact of building social strategies in the culture, structure, and workflow of organizations actually cannot be clearly measured (no data are available with a robust, significant measure of effect), it is, however, known that by adapting organizational and hospitals, toolboxes to a participative perspective. To implement a more flexible perspective may help to add value and create entrepreneurial operating models. In that sense, understanding social media is also now a critical element of every executive's toolkit, whether a government or hospital CEO.

It is recognized that the greatest challenge is to overcome the societal and clinical behaviors and beliefs that currently create barriers to donation.
A case study focused on a paradigmatic and popular storyline ${ }^{48}$ of the TV series Grey's Anatomy demonstrates the impact of two societal myths: VIPs can buy their way to the top of organ waiting lists (purchase myth) and a friendly or parental relationship with professional staff can help receive organ transplants quicker than other individuals (relationship myth). This is the story of the "Duquette" transplantation, where medical doctors linked to the patient by friendship tried to help procure the transplant. Analysis of results revealed that loyal viewers of Grey's Anatomy are less likely to believe the purchase myth, whereas no difference emerged between current viewers and people that do not watch Grey's Anatomy. with respect to the relationship myth. Furthermore, loyal viewers were more likely to talk about their willingness to donate organs than were nonviewers. These findings assessed the role of a medical fiction on perceptions and action tendencies related to organ donation. In Grey's Anatomy, not only in the episodes involving Duquette, but also when describing hospital practices, the notion is that there is no moving up the waiting list other than for severe circumstances, such as an impending death.

On May 1, 2012, the online social network Facebook modified its platform to allow members to specify "Organ Donor" as part of their profile. ${ }^{49}$ Upon such choice, members were offered a link to their state registry to complete an official designation, and their "friends" in the network were made aware of the new status as a donor. Educational links regarding donation were offered to those considering the new organ donor status. On the first day of this initiative, there were 13,054 new online registrations, representing a 21.1fold increase over the baseline average of 616 registrations. Registration rates remained elevated in the following 12 days. It is difficult, however, to weigh the real impact of these registrations. Novel applications of social media may prove effective in increasing organ donation rates and likewise may be utilized in other refractory public health problems where communication and education are essential, but also extremely difficult. ${ }^{49-51}$

These data demonstrate the importance of stimulating thought among citizens by using simple models of communication or targeted donor campaigns..$^{51-54}$

However, debate is now open about social and organizational value of media campaigns instituted by using innovative media, such as TV/movies or social networks: the Spanish model shows social campaigns as having just a secondary role..$^{52-54}$

Probably more than in any other field of medicine, cultural influences are very prominent in transplantation 
due to the complexity of the process and the ethical issues surrounding every step from donation to transplant. Organizations may support perceptions and attitudes toward transplantation, at the same time favoring insights, and communication may contribute as a key, crucial topic in transplantation management.

Indeed, mass media campaigns are widely and successfully used to change health decisions and behaviors for better or for worse in society. In the USA, media campaigns have been launched at local offices of motor vehicle state departments to promote citizens' willingness to register for organ donation and to subsequently donate organs. ${ }^{55}$ The media campaigns include the use of multifaceted communication tools and provide training to desk clerks in the use of scripted ${ }^{55}$ mes- $^{-}$ sages for the purpose of optimizing enrollment in organ donor registries. Integrations with research can support communication. ${ }^{56}$ Certainly, media campaigns give rise to three serious concerns: bias in communicating information with scripted messages without verification of the scientific accuracy of information, the provision of misinformation to future donors that may result in unintended consequences from consenting to medical procedures before death (eg, organ preservation and suitability for transplantation), and the unmanaged conflict of interests for organizations charged with implementing these campaigns (ie, dual advocacy for transplant recipients and donors). ${ }^{55}$

Finally they can help, but may not substitute professional clinical work within hospital and clinical settings.

It is popular to speak of the procurement process as the "gift of life" 57 among pro-donation advocates, transplantation specialists, and within organizations lobbying for improved donation.

Recent sociological research ${ }^{57}$ has shown that assumptions of the gift as one-way, and altruistic approaches, do not necessarily align with people's perceptions and experience of donating body tissues, and that the vocabulary used to describe donor conditions may vary. Studies based on interview data with critical care specialists (intensivists) and donor and recipient coordinators, examined their perceptions of the relevance of the gift topic and its applicability to the context of deceased donation, and describe a great level of variance.

Data indicate several problems with the gift rhetoric to describe the situations health professionals live. As a matter of fact, this terminology tends to focus on the sacrifice involved in tissue donation in general, as well as depoliticizing the exchange relations of tissue transfer in contemporary consumer culture and in the global context. The "gift of life" issue may be appropriate when used in the public domain as a means of publicizing altruistic behaviors, but may not be effective in encouraging them, particularly in some hospital context.

The language to use is an ethical choice and so are the views of health professionals dealing with deceased donation. Although the language of the gift is promoted by ethics committees, legislation, and international organ procurement agencies, and appears in line with ethics protocols, health professionals with longstanding clinical experience of face-to-face interactions with families are not used to mentioning it and consider the gift rhetoric an effective communication tool. It is important to work on this finding, because the language of the gift also separates the act of donation from that of commerce and the commodification of body tissues. This means communicating the distance from donation to commodification and the potential to degrade and exploit human beings, and finally, the positive message that donation is a noble and morally worthy act.

A way to promote the gift issue is to use structured graduate and postgraduate education modeling as a bridging tool.

The Japanese model of education ${ }^{58}$ has modified the education system globally. First, it modified guideline manuals for organ procurement coordination centers to correspond to revised governmental guidelines. Second, all organ procurement coordination centers gathered in a meeting room to learn the new organ procurement system to deal with these guidelines. Third, a special 2-month education program was provided for ten newcomers who also underwent practical training in each donor case along with older organ procurement coordination centers.

Nurse education ${ }^{59-61}$ can offer significant contribution in the organ procurement field. Few intensive care nurses have had extensive experience with or competence and training in organ donation. Nurses working at university hospitals have had more experience, but lesser training than those working in local hospitals. Experience of donor acquisition has had an impact on intensive care nurses' perceptions of their professional competence in the donor process. Discussions on the ward and educational input were seen as important for the further development of professional competence.

Nursing students as future health professionals can become aware of the roles and responsibilities of nurses to augment organ donation and transplantation. According to the opinions of nursing students, the roles of nurses could be classified as "raising public awareness", "care for recipient, donor, and their families", "conducting research", "supporting related organizations", and "being a role model" for the public. As a matter of fact, the responsibilities of nurses to increase organ donation and transplantation are 
not limited to ICUs and emergency units, but also extend to dialysis and hospital patients. The nursing workforce can also be utilized to generate public awareness and is in the zone between hospital clinical pathways of procurement and patients, and citizens' needs. ${ }^{61}$

Similarly, medical students ${ }^{62}$ can also provide their contribution. A Brazilian qualitative study describes a proposed approach on the theme of "transplant and organ and tissue donation" with medical students from a Brazilian university, through a program named "Transplantation League", directly associated with a transplantation center. The league focuses mainly on teaching, research, and practical activities. Education in the hospitals is crucial. ${ }^{63}$ The proposed mechanism of an objective assessment for the early identification of the beating-heart donor should go along with the needs of intensivists to minimize protracted futile care. A welcome compatibility of principles between intensive care and transplantation services can be demonstrated. Derangement of these measurements is usually the prelude to escalation of therapy or additional interventions such as barbiturates, hypothermia, or decompressive craniectomy. In this scenario, given that otherwise objective investigations such as computed tomography (CT) cannot define prognosis except in extreme circumstances such as bilateral hemispheric infarction or herniation, the need for alternative diagnostic options to rationalize continuation or cessation of active care is recognized. ${ }^{64}$

However, in every usual context, the primary goal of intensive care is to actively treat potentially reversible disease or injury, until all efforts are proven useless, rather than to process organ donors. ${ }^{64}$ Defining futility of care has to be both objective and separated from organ donation in an explicit manner if support for proposed withdrawal of care as a prelude to any form of organ donation is to be attained. Working together at educational levels has to merge both goals in parallel: early recognition of donors and steady recognition of life reserves.

Hospitals often organized "audit" and meetings with representatives from the field of clinical neurology, neurotraumatology, intensive care medicine, transplantation medicine, clinical intensive care ethics, and organ procurement management. During these meetings, all possible criteria were discussed to identify patients with a reasonable probability to become brain dead (imminent brain death). They focused on the practical usefulness of two validated coma scales (Glasgow Coma Scale and the Full Outline of UnResponsiveness [FOUR] Score), brain stem reflexes, and respiration to define imminent brain death. ${ }^{64-66}$

Transplant procurement classes first instituted in Spain can be attended all around the world, as Spanish university core curricula are intended as the gold standard of education in this milieu. ${ }^{67}$ Moreover, the Spanish Transplant Procurement Management standard education model, the gold standard, has impacted positively on the various essential levels in the process of organ donation and transplantation, with lifelong follow-up and an international network through the capacity to adapt to specific country needs, as well as continuous quality improvement, thanks to the collaboration of the global networking. Several and differentiated fields of expertise, however, all together, demonstrated the need for coordinated communicational and educational strategies, able to gain new frontiers in a society. Tailored communication strategies together with standardized graduate and postgraduate medical education among health professionals are components of a communication-specific toolbox.

In order to avoid illicit and inacceptable practices and promote the concept that organ donation is a civil right, most transplant centers around the world are also concerned with facing ethical debates. ${ }^{68}$ Efforts from the medical community as well as from governments have contributed to provide solutions to uphold ethical standards in medicine. Organizational tools have to share the ethical concern in order to gain efficacy. ${ }^{69-76}$ Achieving this objective while paying the smallest possible ethical price and without undermining social trust will always be a challenge.

Advocates of presumed consent predict that organ procurements will increase if a change is made from an opt-in or expressed consent approach to their favored opt out (presumed consent) approach. Empirical data, however, do not confirm this assumption, as demonstrated by Spanish example. $^{70}$

On the other hand, brain death or neurologic death has gradually become recognized as the criterion for human death over the past decades worldwide. Nevertheless, in Japan and the states of New York and New Jersey, a person may not be able to be declared legally dead, ${ }^{77,78}$ based on neurologic criteria, even in the state of brain death. In Japan, the 1997 Act on Organ Transplantation legalized brain death determination exclusively when organs were to be procured from brain-dead patients. Even after the 2009 revision, the default definition of death continued to be cardiopulmonary criteria. The renewed interest in donation after cardiocirculatory death started in the 1990s following the limited success of the transplant community to expand the donation after brain-death organ supply and following the request of potential families who are interested in donation after cardiocirculatory death. To affirm brain death independently of procurement as in some European countries may become a legally efficacious tool to procurement. ${ }^{77,78}$ 
As described in government policy strategies, the policy proposed by United Network for Organ Sharing ${ }^{79}$ would use a kidney quality score (the Kidney Donor Profile Index, which relies on factors such as donor age and creatinine in generating a score) to divide allografts into two groups: the best $20 \%$ of kidneys, and the rest. The best $20 \%$ of kidneys would first be offered to the $20 \%$ of wait-listed patients with the longest projected survival. Projected recipient survival would be calculated from a formula consisting of age, history of diabetes, prior transplant, and dialysis vintage. When a "best quality" kidney was offered to the $20 \%$ of "best surviving" patients, rank ordering of those eligible patients would be driven by geography and waiting time (as it is now). Thus, the best quality $20 \%$ of kidneys would be allocated in part by survival-matching of kidney and recipient.

Meanwhile, the other $80 \%$ of kidneys ("lower quality") would be allocated to patients whose age was within 15 years of the donor's age. In this larger group of potential recipients of "lower quality" organs, rank ordering of eligibility would also be driven by geography and waiting time. ${ }^{79,80}$

However, some ethical objections arise against this proposal: it is unfair to older adults to use age as a tool in allocating health care, and those patients with blood types (such as type $\mathrm{O}$ ) who are incompatible with organs from many donors would still face the problem of the lack of compatible kidney allografts. ${ }^{81-83}$

\section{Conclusion}

Our conclusions suggest that organization has a central role in different scenarios of procurement and transplantation in a continuum from government to hospital (the core of the system) and finally among citizens.

To assess the real burden of organization is still a challenge and more work is needed to assess a methodology able to weigh the real impact of different organizational tools.

Ethical concern and communication can be shared between citizenship, society, and clinical professionals.

A standardized hospital pathway definitely remains the essential step.

On the other hand, sustainability of this complex pathway is the challenge of our modern public health and social framework.

A way of living this process can be kaizen (the philosophy of continuous improvement) and respect and empowerment for people, particularly line workers. Both are absolutely required in order to obtain the "Toyota" dimension of lean production to work. ${ }^{84}$
Toyota expert advisors say that one huge barrier to both goals is complacency and a feeling of pride in our achievements when in fact relevant progress has been limited.

To work against the risk of building a self-reflective culture is also likely to contribute to use crises to their advantage; this effort allows us to excel against self-satisfied organizations, which feel they are already the best. ${ }^{83}$

Every step described in this review can be revisited as an opportunity to ameliorate the entire procurement and transplantation milieu. The authors' hypothesis is that the procurement and transplant path can be intended as a production path, and can be supported from three peculiar toolboxes: a policy toolbox where you have to work on structured strategies of allocation, networking, and sharing of clinical evidence; a hospital toolbox focused on team-work along different phases of either procurement or transplantation, referral policy, and graduate and postgraduate education; and finally, a citizenship framework where operating communication tools have to be implemented in order to promote the concept of donation either from ethical or strictly medical standpoints.

All organizational toolboxes are to be instituted with a lean methodology able to check, understand, and manage priorities. This goal is easier to achieve in the clinical pathways of a hospital. More work is needed in the other scenarios described.

Future perspectives include, however, considering cost efficacy and value of maintaining the procurement and transplantation network, especially in the upcoming era of bio-engineering stem cells. ${ }^{85}$ Our standpoint is that the network is a great organizational result of modern medicine: to sustain transplant and procurement networks remains an ethical milestone; to align every step in a "value-obtaining", "waste-avoiding" organizational pathway toward good practices can help.

Procurement and transplantation are extremely complex areas; we suggest using the organizational analogy of a rocket ship: "You cannot get a rocket to the moon just by aiming at it. You also have to give yourself the ability to correct its course. And when we look around at the landscape of really big successes, very often what we see is that the correction" turned out to be more important than the initial direction. As in the Toyota perspective, some goals can be achieved by putting together knowledge and passion. "It's one thing to create all the energy you need to start a lean initiative and way of working, but quite another to keep it going - and that's the real trick" ${ }^{86}$

\section{Acknowledgment}

The authors thank Stan Jordan, for his example of life and research. 


\section{Disclosure}

None of the authors have any conflicts of interest to declare.

\section{References}

1. The Cochrane Library. Available from: http://www.thecochranelibrary. com/view/0/index.html. Accessed August 1, 2014.

2. McKinsey Company. The art of strategy. Mc Kinsey Quarterly. 2013.

3. Rudge C, Matesanz R, Delmonico FL, Chapman J. International practices of organ donation. Br J Anaesth. 2012;108:i48-i55.

4. Organ procurement and transplantation network and scientific registry of transplant recipients 2010 data report. Am J Transplant. 2012;12(Suppl 1):1-156.

5. Reese PP, Friedewald JJ. Profiling live kidney donors in America: cause for optimism and for concern. Clin J Am Soc Nephrol. 2010;5: $1732-1733$.

6. Madwar S. United States officials propose further retreat from first-come, first-served organ donation. CMAJ. 183(10):E639-E640.

7. Garcia G, Harden P, Chapman J. The global role of kidney transplantation. Arch Iran Med. 2012;15:102-106.

8. Wynn JJ,Alexander CE. Increasing organ donation and transplantation: the US experience over the past decade. Transp Int. 2011;24(4):324-332.

9. Murphy PG, Smith M. Towards a framework for organ donation in the UK. Br J Anaesth. 2012;108:i56-i67.

10. Howard K, Jan S, Rose J, et al. Community preferences for the allocation and donation of organs. BMC Public Health. 2011;11:386.

11. Nanni Costa A, De Cillia C, Di Ciaccio P, Rizzato L, Venettoni S. Solid organ transplantation: the Italian experience in the international context. Transplant Proc. 2011;43:2446-2447.

12. Angelico M, Cillo U, Fagiuoli S, et al; Liver Match Investigators. Liver match, a prospective observational cohort study on liver transplantation in Italy: study design and current practice of donor-recipient matching. Dig Liver Dis. 2011;43:155-164.

13. Matesanz R, Domínguez-Gil B, Coll E, de la Rosa G, Marazuela R. Spanish experience as a leading country: what kind of measures were taken. Transp Int. 2011;24:333-343.

14. Matesanz R, Coll E, Domínguez-Gil B, et al. Benchmarking in the process of donation after brain death: a methodology to identify best performer hospitals. Am J Transplant. 2012;12:2498-2506.

15. de la Rosa G, Domínguez-Gil B, Matesanz R, et al. Continuously evaluating performance in deceased donation: the Spanish quality assurance program. Am J Transplant. 2012;12:2507-2513.

16. Rodríguez-Arias D, Wright L, Paredes D. Success factors and ethical challenges of the Spanish model of organ donation. Lancet. 2010;376:1109-1112.

17. Nijboer A, Ulrich F, Bechstein WO, Schnitzbauer AA. Volume and outcome relation in German liver transplant centers: what lessons can be learned? Transplant Res. 2014;3:5.

18. Vathsala A, Chow KY. Renal transplantation in Singapore. Ann Acad Med Singapore. 2009;38:291-299.

19. Kwek TK, Lew WK, Ling Tan H, Kong S. The transplantable organ shortage in Singapore - has implementation of presumed consent to organ donation made a difference? Ann Acad Med Singapore. 2009;38:346-353.

20. Scholda JD, Hallc YN. Enhancing the expanded criteria donor policy as an intervention to improve kidney allocation: is it actually a 'net-zero' model? Am J Transplant. 2010;10:2582-2585.

21. Washburn K, Pomfret E, Roberts J. Liver allocation and distribution: possible next steps. Liver Transplant. 2011;17:1005-1012.

22. Pondrom S. Health-care reform transplant professionals weigh in on the new law's potential impact on the field of transplantation. $\mathrm{Am} \mathrm{J}$ Transplant. 2010;10:1497-1498.

23. Ohkawara H, Fukushima N, Kitagawa T, Ito T, Masutani Y, Sawa Y. Tissue procurement system in Japan: the role of a tissue bank in medical center for translational research, Osaka University Hospital. Issue procurement system in Japan: the role of a tissue bank in medical center for translational research, Osaka University Hospital. Transplant Proc. 2010;42:190-192.
24. Young A, Kim SJ, Speechley MR, et al; Donor Nephrectomy Outcomes Research (DONOR) Network. Accepting kidneys from older living donors: impact on transplant recipient outcomes. Am J Transplant. 2011;11:743-750.

25. Mc Kinsey and Company. Navigating the circular economy: a conversation with Dame Ellen MacArthur, Mc Kinsey Quarterly. 2014. Available from: http://www.mckinsey.com/insights/mckinsey_quarterly. Accessed September 1, 2014.

26. Rey MM, Ware LB, Matthay MA, et al. Informed consent in research to improve the number and quality of deceased donor organs. Crit Care Med. 2011;39:2.

27. Singbartl K, Murugan R, Kaynar AM, et al. Management of braindead donors is associated with an increase in organ recovery for transplantation. Am J Transplant. 2011;11:1517-1521.

28. Perez-Protto S, Mizraji R, Alvarez I. International indicators of donation and solid organ transplantation. Transplant Proc. 2009;41:3460-3461.

29. Murphy F, Cochran D, Thornton S. Impact of a bereavement and donation service incorporating mandatory 'required referral' on organ donation rates: a model for the implementation of the Organ Donation Taskforce's recommendations. Anaesthesia. 2009;64:822-828.

30. Bleakley G. Implementing minimum notification criteria for organ donation in an acute hospital's critical care units. Nurs Crit Care. 2010;15(4):185-191.

31. Manyalich M, Mestres CA, Ballesté C, Páez G, Valero R, Gómez MP. Organ procurement: Spanish transplant procurement management. Asian Cardiovasc Thorac Ann. 2011;19:268-278.

32. Ladina K, Hanto DW. A rational rationing or discrimination: balancing equity and efficiency considerations in kidney allocation. $\mathrm{Am} \mathrm{J}$ Transplant. 2011;11:2317-2321.

33. ANZDATA. Available from: http://www.anzdata.org.au/. Accessed September 1, 2014.

34. CNT. Available from: http://www.trapianti.salute.gov.it/cnt/cntDettaglioMenu.jsp?id= $8 \&$ area $=$ cnt - generale $\&$ menu=menuPrincipale \&sotmenu =donazione\&label=mpd\&livello=1. Accessed September 1, 2014.

35. Salim A, Malinoski D, Schulman D, Desai C, Navarro S, Ley EJ. The combination of an online organ and tissue registry with a public education campaign can increase the number of organs available for transplantation. J Trauma. 2010;69:451-454.

36. Ono VC, Ramalho FS, Rocha JN, et al. Communication between organ donor families and recipients: a definitely controversial subject. Transplant Proc. 2008;40:663-664.

37. Shafi S, Zimmerman B, Kalil R. Temporary inactive status on renal transplant waiting list: causes, risk factors, and outcomes. Transplant Proc. 2012;44:1236-1240.

38. Ivarssona B, Ekmehag B, Sjoberg T. Recently accepted for the waiting list for heart or lung transplantation - patients experiences of information and support. Clin Transplant. 2011;25:E664-E671.

39. Shreststha BM. Strategies for reducing the renal transplant waiting list: a review. Exp Clin Transplant. 2009;7(3):173-179.

40. Rubba F, Mancini G, Giancotti E, et al. La gestione dinamica della lista dei candidati e il sistema Toyota [Federico II University kidney transplant center waiting list management]. Trapianti. 2011;15(2):59-65. Italian.

41. Hong G, Lee KW, Suh S, et al. The model for end-stage liver disease score-based system predicts short term mortality better than the current Child-Turcotte-Pugh score-based allocation system during waiting for deceased liver transplantation. J Korean Med Sci. 2013;28:1207-1212.

42. Klein KB, Stafinski TD, Menon D. Predicting survival after liver transplantation based on pre-transplant MELD score: a systematic review of the literature. PLoS One. 2013;8:e80661.

43. Abolghasemi J, Eshraghian MR, Nasiri Toosi M, Mahmoodi M, Rahimi Foroushani A. Introducing an optimal liver allocation system for liver cirrhosis patients. Hepatitis Mon. 2013;13:e10479.

44. Merion RM, Sharma P, Mathur AK, Schaube DE. Evidence-based development of liver allocation: a review. Transp Int. 2011;24(10): 965-972.

45. Flattau A, Olaywi M, Gaglio PJ, et al. Social barriers to listing for adult liver transplantation: their prevalence and association with program characteristics. Liver Transplant. 2011;17:1167-1175. 
46. Salim A, Berry C, Ley EJ, et al. In-house coordinator programs improve conversion rates for organ donation. J Trauma. 2011;71(3): 733-736.

47. Chui M, Dewhurst M, Pollak L. Building the social enterprise. Mc Kinesy Quarterly. Nov 2013. Available from: http://www.mckinsey. com/insights/mckinsey_quarterly. Accessed November 1, 2014.

48. Brian L. Quick coverage of the organ donation process on Greys Anatomy: the story of Denny Duquette. Clin Transplant. 2009;23: 788-793.

49. Cameron AM, Massie AB, Alexander CE, Stewart B. Social media and organ donor registration: the Facebook effect. Am J Transplant. 2013;13:2059-2065.

50. Chang A, Anderson EE, Turner HT, Shoham D, Hou SH, Grams M. Identifying potential kidney donors using social networking web sites. Clin Transplant. 2013;27:E320-E326.

51. O'Carroll RE, Ferguson E, Hayes PC, Shepherd L. Increasing organ donation via anticipated regret (INORDAR): protocol for a randomised controlled trial. BMC Public Health. 2012;12:169.

52. Oniscu GC, Forsythe JLR. An overview of transplantation in culturally diverse regions. Ann Acad Med Singapore. 2009;38:365-369.

53. Ríos A, López-Navas A, Ayala-García MA, et al. International multicenter opinion study: administrative personnel from Spanish and Mexican health centers faced with human organ donation for transplantation. Transplant Proc. 2010;42:3093-3097.

54. Azuri P, Tabak N. The transplant team's role with regard to establishing contact between an organ recipient and the family of a cadaver organ donor. J Clin Nurs. 2011;21:888-896.

55. Rady MY, McGregor JL, Verheijde JL. Mass media campaigns and organ donation: managing conflicting messages and interests. Med Health Care Philos. 2012;15:229-241.

56. Baldasare D. Linking organ donors and the medical/scientific research community: a US perspective. Cell Tissue Bank. 2011;12:33-35.

57. Shaw R. Perceptions of the gift relationship in organ and tissue donation: views of intensivists and donor and recipient coordinators. Soc Sci Med. 2010;70:609-615.

58. Fukushima N, Konaka S, Kato O, Ashikari J. Professional education and hospital development for organ donation. Transplant Proc. 2012;44:848-850.

59. Meyer K, Bjørk IT, Eide H. Intensive care nurses' perceptions of their professional competence in the organ donor process: a national survey. J Adv Nurs. 2012;68:104-105.

60. Cebeci F, Sucu G, Karazeybek E. The roles of nurses to augment organ donation and transplantation: a survey of nursing students. Transplant Proc. 2011;43:412-414.

61. Ladner DP, Alonso EM, Butt Z, et al. NUTORC - a transdisciplinary health services and outcomes research team in transplantation. Transl Behav Med. 2012;2(4):446-458.

62. Almeida RAM, Quireze C, de Faria WML, dos Santos DF, Dias RV, Maynarde YG. Organ donation and transplantation from medical students' perspective: introducing the experience from an academic league in Brazil. Transplant Proc. 2011;43:1311-1312.

63. D'Alessandro AM, Peltierc JW, Dahlc AJ. The impact of social, cognitive and attitudinal dimensions on college students' support for organ donation. Am J Transplant. 2012;12(1):152-161.

64. Bell MDD. Early identification of the potential organ donor: fundamental role of intensive care or conflict of interest? Intensive Care Med. 2010;36:1451-1453.

Transplant Research and Risk Management

\section{Publish your work in this journal}

Transplant Research and Risk Management is an international, peerreviewed open access journal focusing on all aspects of transplantation and risk management to achieve optimal outcomes in the recipient improving survival and quality of life. The journal welcomes submitted papers covering original research, basic science, clinical studies,
65. Callender CO, Miles PV. Minority organ donation: the power of an educated community. J Am Coll Surg. 2010;210(5):708-715.

66. de Groot YJ, Jansen NE, Bakker J, et al. Imminent brain death: point of departure for potential heart-beating organ donor recognition. Intensive Care Med. 2010;36:1488-1494.

67. Paez G, Valero R, Manyalich M. Training of health care students and professionals: a pivotal element in the process of optimal organ donation awareness and professionalization. Transplant Proc. 2009;41: 2025-2029.

68. Trey T, Caplan AL, Lavee J. Transplant ethics under scrutiny responsibilities of all medical professionals. Croat Med J. 2013;54: 71-74.

69. Hershenov DB, Delaney JJ. The metaphysical basis of a liberal organ procurement policy. Theor Med Bioeth. 2010;31:303-305.

70. Delaney J, Hershenov DB. Why consent may not be needed for organ procurement. Am J Bioeth. 2009;9:3-10.

71. Shetty P. Tax cuts for organs? Lancet. 2009;374(9698):1315-1316.

72. Hagan M. Quality initiatives in transplantation. Prog Transplant. 2009;19(3):206-207.

73. Miller FG. Death and organ donation: back to the future. J Med Ethics. 2009;35:616-620.

74. Kirby J. Is context a distortional factor, really? Am J Bioeth. 2009;9(8):20-21.

75. Ghaly M. The ethics of organ transplantation: how comprehensive the ethical framework should be? Med Health Care Philos. 2012;15:175-179.

76. Caillé Y, Doucin M. Conceptions guiding the organization of organ procurement and transplantation in France, Canada and the United States. Néphrol Thér. 2011;7:59-66.

77. Kato Y. Conscience in health care and the definitions of death. Croat Med J. 2013;54:75-77.

78. Le Dinh H, de Roover A, Kaba A. Donation after cardio-circulatory death liver transplantation. World J Gastroenterol. 2012;18(33): 4491-4506.

79. Reese PP, Caplan AL. Better off living - the ethics of the new UNOS proposal for allocating kidneys for transplantation. Clin J Am Soc Nephrol. 2011;6:2310-2312.

80. Dobbels F, Hames A, Aujoulat I, Heaton N, Samyn M. Should we retransplant a patient who is non-adherent? A literature review and critical reflection. Pediatr Transplant. 2012;16:4-11.

81. Hoffmann PJ. The most altruistic living organ donor: a best friend. J Am Osteopath Assoc. 2011;111:445-449.

82. Petrini C. Ethical issues with nondirected ("good samaritan") kidney donation for transplantation. Transplant Proc. 2011;43:988-989.

83. McKinsey Company. The disruptive power of collaboration: an interview with Clay Shirky. Mc Kinsey Quarterly. Mar 2014. Available from: http://www.mckinsey.com/insights/mckinsey_quarterly. Accessed March 1, 2014.

84. Ohler L. Courage and character, leaders and legends: an interview with Stan Jordan. Prog Transplant. 2010;20(4):303-304.

85. Badylak S, Weiss D, Caplan A, Macchiarini P. Engineered whole organs and complex tissues. Lancet. 2012;379:1-10.

86. Deryl Sturdevant. (Still) learning from Toyota. Mc Kinsey Quarterly. Mar 2014. Available from: http://www.mckinsey.com/insights/ mckinsey_quarterly. Accessed March 1, 2014.

reviews \& evaluations, guidelines, expert opinion and commentary, case reports and extended reports. The manuscript management system is completely online and includes a very quick and fair peer-review system, which is all easy to use. Visit http://www.dovepress.com/ testimonials.php to read real quotes from published authors. 